\title{
Phenolic Compounds Contaminants in Water: A Glance
}

\author{
Kalidas Mainali* \\ Washington State University, USA
}

*Corresponding author: Kalidas Mainali, Washington State University, USA.

\begin{abstract}
Water is the fundamental importance for all living organisms on earth. Among the organic pollutants encountered in water, phenol and its derivatives are important to identify and quantify them. It is because of their detrimental effects on aquatic organisms as well as human being. The use of fast detection technique such as spectrophotometric technique, electrochemical methods, and biosensor have practical implication. Furthermore, the use of hybrid technology can be used to remove phenolic from wastewater etc.
\end{abstract}

Keywords: Phenol; Dissolved organic matter; Fluorescence methods

\section{Introduction}

The environmental contaminations of natural lakes, rivers, reservoirs and ocean water can be classified according to contamination triggered by organic chemicals, inorganic chemicals, microorganisms etc. It is because of the rapid growth of population and industry development, the wide use of diverse chemicals in the industry is increasing. Because of bad disposal practices and before the strict guidelines were outlined under the first federal hazardous waste mandate - the Resource Conservation and Recovery Act of 1976 (RCRA), these chemicals were disposed in pits/ ponds and lagoons and are still polluting the environment [1]. For example, the contamination of soil and groundwater by improper treatment of hazardous substances and contaminating the water system by inflowing wastewater containing hazardous substances [2]. By this process, it harms living organisms and ecosystems as well as human health via bioaccumulation, contamination of public water supply and recreational use of contaminated water resources. Also, the contamination of water and soil can hinder the growth of agricultural products and contaminants can accumulate in the products. It is due to the advancement of technology and rapid industrial growth, freshwater resources all over the world are threatened. It is seen that developed countries suffer from chemical discharges problems, whereas developing countries from agricultural sources. Basically, the contaminants associated with water pollution can be categorized as follows [3]: Agricultural chemicals generally include organochlorine compounds. They are extremely toxic and when a human being is exposed to them, they can suffer from internal and neurological diseases. These are also considered as carcinogenic substances. It is because these compounds are exposed to people's health through drinking water, it is important to identify, quantify and treatment them. Typical organo-chlorinated compounds are trichloroethylene and tetrachloroethylene (PCE) which are mainly used as solvents or as dry-cleaning agents. Generally, these chemicals are highly soluble, contaminate the environment by seeping into the ground with rainwater. Monosubstituted benzenes, polyaromatic hydrocarbons are most common hazardous wastes.

Moreover, numerous aliphatic and aromatic compounds are used in the synthesis of pesticides, plastics, artificial fibers (e.g. nylon, polyester, acrylics), dyestuffs, paints and other useful consumer products. Among these industrial intermediates, the chlorobenzenes, chlorophenols are most common and found as contaminants in aqueous industrial intermediates. Similarly, dioxins are the best-known organic compounds, also called polychlorinated dibenzo-p-dioxin (PCDD) and polychlorinated dibenzofuran (PCDF) [1]. Different kinds of PCDD and PCDF have been reported in the literature and these contaminants are very toxic to a human being 
which causes carcinogenic, immunotoxin, and to have toxic effects on reproduction. These chemical contaminants are persistent organic pollutants and resist decomposition in the environment. Inorganic chemicals that also cause contamination include cyanide, nitrite, nitrate, and heavy metals such as cadmium, mercury, lead and arsenic. Heavy metals and cyanide are extremely toxic, and many of these substances are acutely toxic and carcinogenic. Contamination by nitrate and nitrite in groundwater is generally caused by excessive application of chemical fertilizers, inappropriate control of waste material from animal husbandry, and seepage of domestic wastewater into the ground. They can get into drinking water from natural sources, industrial processes, as well as from plumbing systems. Similarly, heavy metals contamination generally occurs from the inappropriate discharged from mine and get contaminated with water resources [1]. Besides these, biological and radiological contaminants are also found in water. Radiological contaminants are caused by radioactive elements. These elements tend to be a greater problem in groundwater as compared to surface water. The potential sources of these materials could be soil or rocks in which water moves via some industrial waste [4].

\section{Dissolved organic matter and nonpolar organic pollutants}

Reuse of urban wastewater is considered as an important component of sustainable wastewater management practices, mainly for non-potable applications. Particularly, their use in irrigation is increasing the number of benefits relating to the enhancement of water balances and soil enrichment by the nutrients in the treated effluents. However, the hidden drawback of dissolved organic matter (DOM) or heterogeneous effluent organic matter needs to be considered seriously as it is persistent and difficult to treat cost-effectively in wastewater [5]. Polycyclic aromatic compounds (PAHs) are commonly found everywhere as semi-volatile contaminants in water, air, soil and food matrices. They are mainly by-products of incomplete combustion of organic substances and generated by fossil fuels or plants burning. Similarly, PAHs consist of hundreds of separate chemicals that occur together as in mixtures. They are also known to be toxic to aquatic animals and humans. It is due to higher molecular weight, they are stable, persist in the environment longer, and are less water soluble and more toxic. These PAHs in streams and lakes are thought to rarely pose a human health risk via drinking water because of their tendency to attach to particles rather than dissolve in water. However, United States Environmental Protection Agency (USEPA) has a maximum contaminant level (MCL) for PAH in drinking water of $0.2 \mathrm{ppb}$ of drinking water. In natural waters, organic matters exist in dissolved, colloidal and particulate. However, dissolved organic matter (DOM) is the most important and studied fraction. The presence of rapidly degradable, the labile organic matter is of interest with a view to the analysis of river water quality. Additionally, dissolved organic carbon (DOC) constitutes a parameter of organic pollution for waters and wastewater which is not so often studied. Since most of the fraction of it is not bio-gradable, it is expected to effect on wastewater treatment plant. So, DOC is undesirable in the effluent, also causes color and order of water [6]. In literature, fluorescence studies have been carried out in the aquatic environment to know all about DOM. However, the most commonly studied fluorescent organic components of natural water include humic substances [7].

\section{Phenolic and polyphenolic compounds}

Among the different contaminants described above, phenolic and polyphenolic compounds are belong to organic compounds and widely distributed in the environment including wastewater and natural environmental waters [8]. Phenolic compounds are among the chemicals of major concern, it is because of their tendency of persistent in the environment for a long period of time and toxic effects. In fact, they are introduced to the environment in variety of ways like waste from paper manufacturing, agriculture, pharmaceuticals, petrochemical industry, coal processing or as municipal wastes [9]. The phenolic micropollutants generally include chloro, bromo, and nitro and alkyl phenol. It is because of its toxicity and persistence in the environment, these phenolic compounds are considered as priority pollutants and appear in a list of dangerous substances of the US Environmental Protection Agency (EPA). Discharge of these compounds without treatment may lead to serious health risks to humans, animals, and aquatic systems. International regulatory bodies have set strict discharge limits for phenols for sustainable environment. For example, the EPA has set a water purity standard of less than $1 \mathrm{ppb}$ for phenol in surface water [10]. The toxicity levels usually are in the range 9-25 $\mathrm{mg} / \mathrm{L}$ for both humans and aquatic life [4]. Similarly, phenyl phenols and Bisphenols are widely used in hospitals and households as a disinfectant. They are also use in cosmetics, leather, and textile and paper industry. Wide range of application of these compounds caused their presence in many parts of the environment such as surface water, sewage sludge and in marine sediments. It was reported that the exposure of these compounds affects the endocrine system, showing estrogenic activity [11].

All these phenolic compounds possess hazardous health effects that can be both acute and chronic. Long-term exposure to phenols can lead to irregular breathing, muscle weakness and respiratory arrest at lethal doses in humans. Also, chronic exposure to phenols leads to irritation in the gastrointestinal and central nervous systems in liver, growth retardation and abnormal development in the offspring of animals. Therefore, an easily applied, sensitive, selective method is required for monitoring of the phenolic compounds concentration in environmental waters. In the past, many analytical methods were proposed for determination of phenol and its derivatives in natural environmental waters and wastewaters. The most widely used were gas chromatography, high-performance liquid chromatography, LC-MS/MS etc. [12]. Though these are convenient and popular, they have some drawbacks such as complicated sample treatment, complicate and time-consuming procedures and require expensive equipment. Also, they are inadequate for routine analysis. A new mechanism is still needed to provide targeted high-quality monitoring information on the concentration of the most relevant emerging 
pollutants such as phenolic compounds for the risk assessment across water resources. The situation of water pollution in the USA is still serious, with huge challenges to safe drinking and sudden source water pollution problems arising day by day. Therefore, rapid and sensitive detection of phenol in water is vital. In literature, fluorescence spectroscopy is described as a useful diagnostic tool to evaluate many polycyclic aromatic compounds in complex matrices. Despite the ability to select both the excitation and the emission wavelengths, conventional fluorescence methods have limited practical applicability [13]. It is due to advancement in technology, compared to conventional fluorometry, synchronous fluorescence scan seems promising. The ability to analyze complex multi-component mixtures without resorting to tedious separation procedure is extremely useful for routine analysis. Alternatively, fluorescence quenching is another step that provides extra sensitivity and selectivity [14]. This kind of selective fluorescence quenching obviously helps to avoid undesired fluorescence from the slightly different molecular structure. Additionally, electrochemical methods are also the reliable tools for the fast and low-cost assay for the phenolic compounds (phenolic) in the mixture. In literature, it has been reported methods for the detection of phenolic compounds based on several types of enzymes such as tyrosinase, laccase etc. [15]. Liu et al., studied large organic contaminants (mainly produced by industries) like phenol and o-cresol which could be harmful to people and environment. In these studies, they proposed a new electrochemical approach that could simultaneously determine the phenol and o-cresol [16].

In literature, conventional methods have been applied such as steam distillation, liquid-liquid extraction, solid phase extraction, wet air oxidation, catalytic wet air oxidation and biodegradation for removal of phenols. However, it is due to using of high volumes of chemicals and some limitations of technologies, they are not so practical to use on a routine basis. On the other hand, advanced technology such as Fenton process, ozonation, photochemical treatments are effective but also has some limitations like high energy cost and environmental pollution. As compared these physiochemical treatments to others, biological treatment seems environmentally friendly and energy saving [4]. Therefore, it is necessary to focus research on enzymatic treatment method to remove phenolic from contaminated water. Furthermore, in the true sense, no technology independently counters all the problems. That is why the concept of hybrid technology should be considered. Since technological solution heavily depends on raw water characteristic, affordability, and acceptability, it is very important to identify and quantify them first.

\section{Conflict of Interest}

No conflict of interest.

\section{References}

1. Watts RJ (1998) Hazardous wastes: sources, pathways, receptors.

2. Strifling D (2017) Reducing Chloride Discharges to Surface Water and Groundwater: A Menu of Options for Policymakers.

3. Tang WZ (2016) Physicochemical treatment of hazardous wastes, CRC Press, USA.

4. Sharma S, Bhattacharya A (2017) Drinking water contamination and treatment techniques. Applied Water Science 7(3): 1043-1067.

5. Michael-Kordatou I, Michael C, Duan X, He X, Dionysiou DD, et al. (2015) Dissolved effluent organic matter: characteristics and potential implications in wastewater treatment and reuse applications. Water research 77: 213-248.

6. Katsoyiannis A, Samara C (2007) The fate of dissolved organic carbon (DOC) in the wastewater treatment process and its importance in the removal of wastewater contaminants. Environmental Science and Pollution Research-International 14(5): 284-292.

7. Hudson N, Andy B, Darren R (2007) Fluorescence Analysis of Dissolved Organic Matter in Natural, Waste and Polluted Waters-A Review. Willey Online Library 23(6): 631-649.

8. Stelmaszewski A (2012) Application of fluorescence in studies of marine petroleum pollutants. Zeszyty Naukowe Akademii Morskiej w Gdyni(76): 74-83.

9. Sun R, Wang Y, Ni Y, Kokot S (2014) Spectrophotometric analysis of phenols, which involves a hemin-graphene hybrid nanoparticles with peroxidase-like activity. Journal of hazardous materials 266: 60-67.

10. Kazemi P, Mohammad P, Alireza B, Toraj M, Omid B (2014) Stability and extraction study of phenolic wastewater treatment by supported liquid membrane using tributyl phosphate and sesame oil as liquid membrane. Chemical engineering research and design 92(2): 375-383.

11. Olak M, Marta G, Jacek SM (2012) Phenolic compounds in the environment-occurrence and effect on living organisms. Proceedings of ECOpole.

12. Monasterio RP, Ariel RF, María FS (2014) Matrix solid-phase dispersion: a simple and fast technique for the determination of phenolic compounds in olive oil by liquid chromatography. Analytical Methods 6(22): 89868995.

13. Patra D (2003) Applications and new developments in fluorescence spectroscopic techniques for the analysis of polycyclic aromatic hydrocarbons, Applied Spectroscopy Reviews 38(2): 155-185.

14. Park SA, Eunji J, Won-Gun K, Bumsang K (2010) Fabrication and characterization of optical biosensors using polymer hydrogel microparticles and enzyme-quantum dot conjugates. Sensors and Actuators B: Chemical 150(1): 120-125.

15. Dobes J, Ondrej Z, Jiri S, Branislav RN, Petr B, et al. (2013) Electrochemical tools for determination of phenolic compounds in plants. A review. Int J Electrochem Sci 8: 4520-4542.

16. Liu J, Hua H, Sheng Z, Xichun S, Dulin Y (2016) Electrochemical Simultaneously Determination of Phenol and o-Cresol in Water Based on ZnO Nanosheets. Int J Electrochem Sci 11: 3921-3930.

\section{Acknowledgement}

None. 